\title{
Modeling and Control of Primary Parallel Isolated Boost Converter
}

Mira Albert, Maria del Carmen; Hernandez Botella, Juan Carlos; Sen, Gökhan; Thomsen, Ole Cornelius; Andersen, Michael A. E.

\section{Published in:}

Proceedings of 38th Annual Conference on IEEE Industrial Electronics Society - IECON 2012

Link to article, DOI:

10.1109/IECON.2012.6388766

Publication date:

2012

Document Version

Peer reviewed version

Link back to DTU Orbit

Citation (APA):

Mira Albert, M. D. C., Hernandez Botella, J. C., Sen, G., Thomsen, O. C., \& Andersen, M. A. E. (2012). Modeling and Control of Primary Parallel Isolated Boost Converter. In Proceedings of 38th Annual Conference on IEEE Industrial Electronics Society - IECON 2012: 38th Annual Conference on IEEE Industrial Electronics Society (pp. 554-559). IEEE. https://doi.org/10.1109/IECON.2012.6388766

\section{General rights}

Copyright and moral rights for the publications made accessible in the public portal are retained by the authors and/or other copyright owners and it is a condition of accessing publications that users recognise and abide by the legal requirements associated with these rights.

- Users may download and print one copy of any publication from the public portal for the purpose of private study or research.

- You may not further distribute the material or use it for any profit-making activity or commercial gain

- You may freely distribute the URL identifying the publication in the public portal 


\title{
Modeling and Control of Primary Parallel Isolated Boost Converter
}

\author{
Maria C. Mira A., Juan C. Hernandez B., Gokhan Sen, Ole C. Thomsen, Michael A. E. Andersen \\ Technical University of Denmark \\ Ørsteds Plads, 349. Kgs. Lyngby, Denmark
}

s101905@student.dtu.dk, s101901@student.dtu.dk,gs@elektro.dtu.dk, oct@elektro.dtu.dk,ma@elektro.dtu.dk

\begin{abstract}
In this paper state space modeling and closed loop controlled operation have been presented for primary parallel isolated boost converter (PPIBC) topology as a battery charging unit. Parasitic resistances have been included to have an accurate dynamic model. The accuracy of the model has been tested by comparing the calculated and measured loop gains. The designed controller has been implemented in a DSP based control circuit and stable operation of the converter has been achieved.
\end{abstract}

Index Terms-Battery, fuel cell, isolated boost converter, statespace averaging.

\section{NOMENCLATURE}

$R_{D_{\text {Bat }}} \quad$ Battery dynamic resistance

$V_{O C_{B a t}} \quad$ Battery open circuit voltage

$r_{L} \quad$ Inductor parasitic resistance

$r_{M P} \quad$ Primary MOSFET's on resistance

$r_{p} \quad$ Transformer primary resistance

$r_{S} \quad$ Transformer secondary resistance

$r_{M S} \quad$ Secondary MOSFET's on resistance

$r_{\text {esr }} \quad$ Capacitor series resistance

$v_{O}{ }^{\prime} \quad$ Reflected output voltage

\section{INTRODUCTION}

$\mathrm{V}$ OLTAGES and/or currents in power electronics circuits need to be regulated around a desired reference value. This is done by adjusting the duty cycle of the controllable switches in a proper way to have the required dynamic behavior. The duty cycle is adjusted by filtering and scaling the error through a compensator which is designed based on an accurate model of the converter [1]. Modeling of switch mode converters have been studied widely in the literature [2][5]. A common method used in dc-dc converter modeling is state space averaging [6]-[8]. By using this method, it is possible to represent converter switching states in terms of state space matrices and obtain the small signal model of the converter.

PPIBC is an isolated boost type dc-dc converter topology suitable for low voltage and high current on the input side as shown in Fig. 1 [10]. The two parallel full bridges with their respective transformers work synchronously with the switches in the same positions turning on and off at the same time. This makes the converter operation similar to simple isolated boost converter. The current balancing transformer (CBT) is practically an inverse coupled inductor which only acts as high impedance in case of an imbalance between the two full bridge currents. Fig. 2 shows some key waveforms of operation.

In this paper non-ideal modeling and closed loop control of PPIBC have been investigated. The target application of the converter is a battery charging unit in a fuel cell based vehicle. In fuel cell applications input current is the main parameter to be controlled due to the unique I-V characteristics of the device [9]. For this reason boost type converter topologies are suitable for fuel cell applications, since one of the state variables of the converter is the input inductor current which is in the fuel cell side. On the other hand, battery as a load is quite different in ac small signal terms, compared to pure resistive load which generally is taken as the case for converter dynamic modeling. In addition, due to the battery terminal voltage difference during charging and discharging, the dc operating point of the converter will change modifying the gain of the plant transfer function. That is why designing a controller based on a resistive load may not work for a converter with battery loading in the end application. Based on the above arguments a detailed model has been derived in this paper including component non-idealities. Due to the low dynamics of the fuel cell battery charging system there is no high bandwidth requirement for the converter. In addition, as a result of the phase erosion in the control loop due to signal conditioning and digital control delay, an upper limit naturally appears in the achievable control loop bandwidth. Therefore, a DSP based controller has been implemented whose pole and zero locations have been selected to achieve a $1 \mathrm{kHz}$ loop bandwidth. The compensated loop gain and phase of the converter have been measured and compared to the derived model.

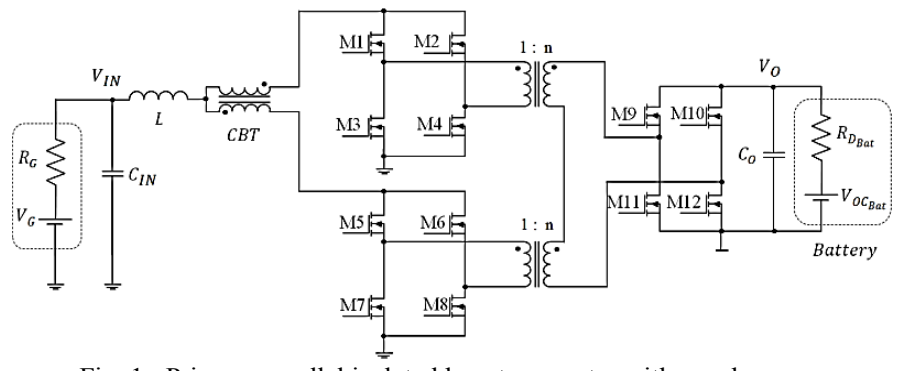

Fig. 1. Primary parallel isolated boost converter with synchronous rectification. 


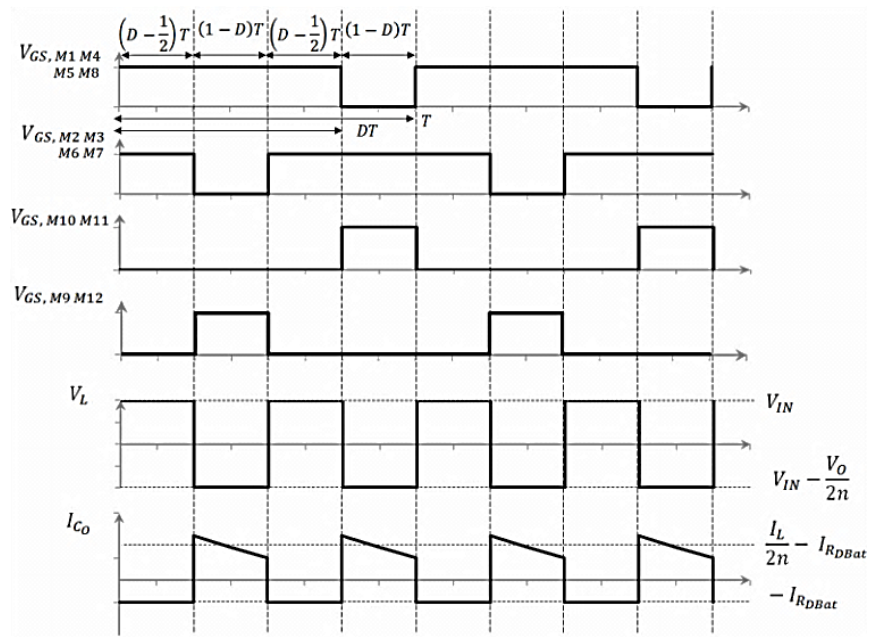

Fig. 2. Steady state operating waveforms.

\section{CONVERTER MODELING}

In this section PPIBC will be modeled including parasitic resistances of the circuit components. The output voltage is fixed by the battery, thus to achieve fuel cell power regulation only inductor current will be controlled. In order to obtain the duty ratio-to-inductor current transfer function state space averaging is performed by obtaining the two linear subcircuits in the charging and discharging switching states. Each switching state can be expressed in terms of state space equations, Eq. (1) and Eq. (2). However, the output equation (2) will not be employed since inductor current is already a state variable.

$$
\begin{gathered}
\frac{d x(t)}{d t}=A x(t)+B u(t) \\
y(t)=C x(t)+D u(t)
\end{gathered}
$$

Fig. 3 shows the inductor charging period where all the primary switches are conducting, the secondary switches are off and the load current is supplied by the output capacitor. A simplified version of Fig. 3 can be obtained by reflecting the secondary side components to the primary side as shown in Fig. 4.

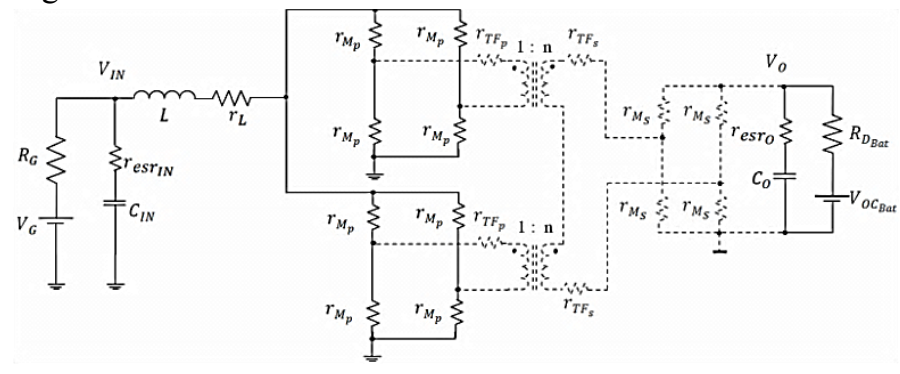

Fig. 3. Charging period equivalent circuit.

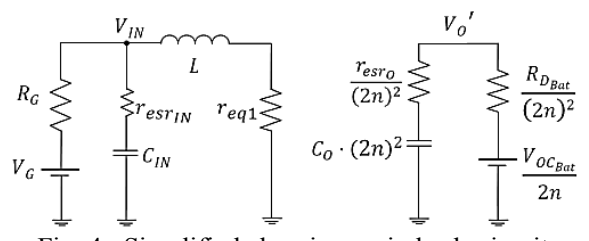

Fig. 4. Simplified charging period sub-circuit.

Parasitic resistances of the input inductor and the primary switches can be grouped as equivalent resistance $r_{e q 1}=$ $r_{L}+r_{M_{P}} / 2$; also the reflected output voltage is defined as $v_{o}^{\prime}=v_{o} / 2 n$. The dynamic equations during the charging state can be obtained by evaluating the derivatives of the inductor current and the input and output capacitor voltages as shown in (3), (4) and (5).

$$
\begin{gathered}
L \cdot \frac{d i_{L}(t)}{d t}=v_{I N}(t)-i_{L}(t) \cdot r_{e q 1} \\
C_{I N} \cdot \frac{d v_{C_{I N}}(t)}{d t}=\frac{v_{I N}(t)-v_{C_{I N}}(t)}{r_{e s r_{I N}}} \\
C_{O} \cdot(2 n)^{2} \cdot \frac{d v_{C_{O}}(t)}{d t}=\frac{v_{O}{ }^{\prime}(t)-v_{C_{O}}(t)}{r_{e s r_{O}} /(2 n)^{2}}
\end{gathered}
$$

Expressions of $v_{I N}$ and $v_{O}$ ' for the charging period are given in (6) and (7).

$$
\begin{gathered}
v_{I N}(t)=\frac{V_{G} \cdot r_{e s r_{I N}}+v_{C_{I N}}(t) \cdot R_{G}-i_{L}(t) \cdot\left(R_{G} \cdot r_{e s r_{I N}}\right)}{R_{G}+r_{e s r_{I N}}} \\
v_{O}^{\prime}(t)=\frac{\frac{V_{O C_{B a t}}}{2 n} \cdot r_{e s r_{O}}+v_{C_{O}}(t) \cdot R_{D_{B a t}}}{R_{D_{B a t}}+r_{e s r_{O}}}
\end{gathered}
$$

Rearranging (3), (4) and (5) in the state space matrix form given in Eq. (8) results in Eq. (9).

$$
\frac{d x(t)}{d t}=A_{1} x(t)+B_{1} u(t)
$$

Fig. 5 shows the inductor discharge period where two diagonal switches are conducting in each full bridge on the primary side. The two transformers are actively transferring power through two corresponding diagonal switches on the secondary side.

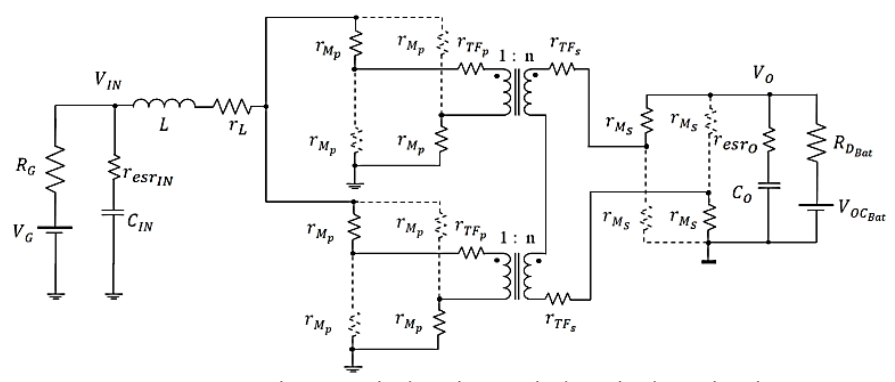

Fig. 5. Discharging period equivalent circuit.

$\frac{d}{d t}\left[\begin{array}{c}i_{L}(t) \\ v_{C_{I N}}(t) \\ v_{C_{O}}(t)\end{array}\right]=\left[\begin{array}{ccc}-\frac{1}{L}\left(r_{e q 1}+\frac{r_{e s r_{I N}} \cdot R_{G}}{R_{G}+r_{e s r_{I N}}}\right) & \frac{R_{G}}{L\left(R_{G}+r_{e s r_{I N}}\right)} & 0 \\ -\frac{R_{G}}{C_{I N}\left(R_{G}+r_{e s r_{I N}}\right)} & -\frac{1}{C_{I N}\left(R_{G}+r_{e s r_{I N}}\right)} & 0 \\ 0 & 0 & -\frac{1}{C_{O}\left(R_{D_{B a t}}+r_{e s r_{O}}\right)}\end{array}\right] \cdot\left[\begin{array}{c}i_{L}(t) \\ v_{C_{I I}}(t) \\ v_{C_{O}}(t)\end{array}\right]+\left[\begin{array}{cc}\frac{r_{e s r_{I N}}}{L\left(R_{G}+r_{e s r_{I N}}\right)} & 0 \\ 0 & 1 \\ \frac{1}{C_{I N}\left(R_{G}+r_{e s r_{I N}}\right)} & 0 \\ 0 & \frac{1}{2 C_{o} n\left(R_{D_{B a t}}+r_{e s r o}\right)}\end{array}\right] \cdot\left[\begin{array}{c}V_{G} \\ V_{o C_{B a t}}\end{array}\right]$ 
Simplifying the sub-circuit in Fig. 5 leads to the circuit shown in Fig. 6. Here the two transformers are combined to a single transformer with an equivalent turn ratio. Furthermore, the transformer in Fig. 6 can also be eliminated by reflecting the impedances on the secondary side to the primary side as shown in Fig. 7.

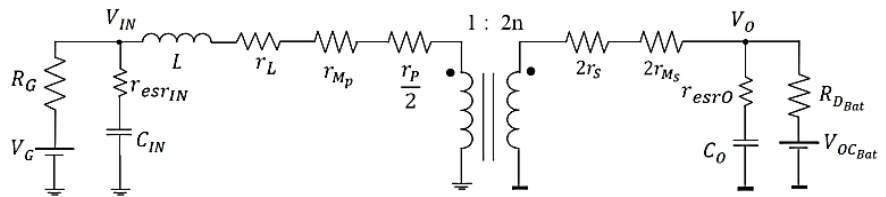

Fig. 6. Equivalent discharging period sub-circuit.

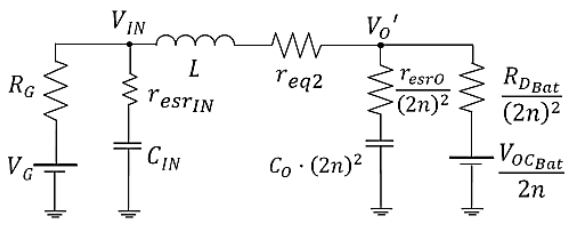

Fig. 7. Simplified sub-circuit with reflected secondary side impedances.

The equivalent resistance $r_{e q 2}$ is given by Eq. (10).

$$
r_{e q 2}=r_{L}+r_{M_{P}}+\frac{r_{P}}{2}+\frac{2 r_{S}}{(2 n)^{2}}+\frac{2 r_{M_{S}}}{(2 n)^{2}}
$$

The inductor and capacitor equations for the discharging switching state can be written as in Eq. (11), Eq. (12) and Eq. (13).

$$
\begin{gathered}
L \cdot \frac{d i_{L}(t)}{d t}=V_{I N}(t)-i_{L}(t) \cdot r_{e q 2}-v_{O}{ }^{\prime}(t) \\
C_{I N} \cdot \frac{d v_{C_{I N}}(t)}{d t}=\frac{V_{I N}(t)-v_{C_{I N}}(t)}{r_{e s r_{I N}}} \\
C_{O} \cdot(2 n)^{2} \cdot \frac{d v_{C_{O}}(t)}{d t}=\frac{v_{O}{ }^{\prime}(t)-v_{C_{O}}(t)}{r_{e s r_{O}} /(2 n)^{2}}
\end{gathered}
$$

Expressions of $v_{I N}$ and $v_{O}^{\prime}$ for the discharging state are given in (14) and (15).

$$
\begin{gathered}
v_{I N}(t)=\frac{V_{G} \cdot r_{e s r_{I N}}+v_{C_{I N}}(t) \cdot R_{G}-i_{L}(t) \cdot\left(R_{G} \cdot r_{e s r_{I N}}\right)}{R_{G}+r_{e s r_{I N}}} \\
v_{O}{ }^{\prime}(t)=\frac{V_{O C_{B a t}} / 2 n \cdot r_{e s r_{O}}+v_{C_{O}}(t) \cdot R_{D_{B a t}}+\frac{i_{L}(t)}{(2 n)^{2}} \cdot\left(R_{D_{B a t}} \cdot r_{e s r_{O}}\right)}{R_{D_{B a t}}+r_{e s r_{O}}}
\end{gathered}
$$

Eq. (11), Eq. (12) and Eq. (13) can be written in the form of Eq. (16). The state and input matrices of the discharging subinterval can be expressed as in Eq. (17).

$$
\frac{d x(t)}{d t}=A_{2} x(t)+B_{2} u(t)
$$

The two switching states are averaged over the switching period using Eq. (18) and Eq. (19).

$$
\begin{aligned}
& A=A_{1} \cdot d+A_{2} \cdot(1-d) \\
& B=B_{1} \cdot d+B_{2} \cdot(1-d)
\end{aligned}
$$

All the variables are perturbed around a quiescent operating point $X$. This results in $(X+\hat{x})$ where $X \gg \hat{x}$. Eliminating the $\mathrm{dc}$ and the second order terms gives the first order linear model shown in Eq. (20).

$$
\dot{\hat{x}}=A \cdot \hat{x}+B \cdot \hat{u}+\left[\left(A_{1}-A_{2}\right) X+\left(B_{1}-B_{2}\right) U\right] \cdot \hat{d}
$$

The steady state solution in Eq. (20) can be obtained by manipulation of matrices $\mathrm{A}$ and $\mathrm{B}$ as shown in Eq. (21).

$$
X=-A^{-1} \cdot B \cdot U
$$

The duty cycle-to-inductor current transfer function is obtained by setting the input voltage perturbation to zero.

$$
G_{i_{L}}=\left.\frac{\hat{\imath}_{L}(s)}{\hat{d}(s)}\right|_{\widehat{u}(s)=0}
$$

The symbolic expression for $G_{i_{L}}$ has been obtained using MATLAB; however, it has not been included in here due to space limitation. The gain and phase plots of Eq. (22), required for controller design purposes, has been obtained using the values given in Table I and Table II, as shown in Fig.9 and Fig. 10.

TABLE I

PARAMETERS OF THE CONVERTER

\begin{tabular}{cc}
\hline \hline Input Voltage & $36 \mathrm{~V}$ \\
Output Voltage & $48 \mathrm{~V}$ \\
Turn ratio & $1: 3$ \\
Inductor & $13.4 \mu \mathrm{H}$ \\
Transformer and inductor & Ferrite $3 \mathrm{~F} 3$ \\
core material & $40 \mu \mathrm{H}$ \\
Capacitor $C_{I N}$ & $120 \mu \mathrm{H}$ \\
Capacitor $C_{O}$ & $\mathrm{FDH} 055 \mathrm{~N} 15$ \\
Switches M1-M8 & $50 \mathrm{kHz}$ \\
Switches M9-M12 & \\
Switching frequency & \\
\hline \hline & \\
CONVERTER PARASITIC RESISTANCES \\
\hline \hline$r_{L}$ & $3.9 \mathrm{~m} \Omega$ \\
$r_{M P}$ & $7.5 \mathrm{~m} \Omega$ \\
$r_{p}$ & $3.5 \mathrm{~m} \Omega$ \\
$r_{S}$ & $0.4 \mathrm{~m} \Omega$ \\
$r_{M S}$ & $5.9 \mathrm{~m} \Omega$ \\
$r_{e s r_{I N}}$ & $3.15 \mathrm{~m} \Omega$ \\
$r_{e s r_{O}}$ & $1.1 \mathrm{~m} \Omega$ \\
\hline \hline
\end{tabular}

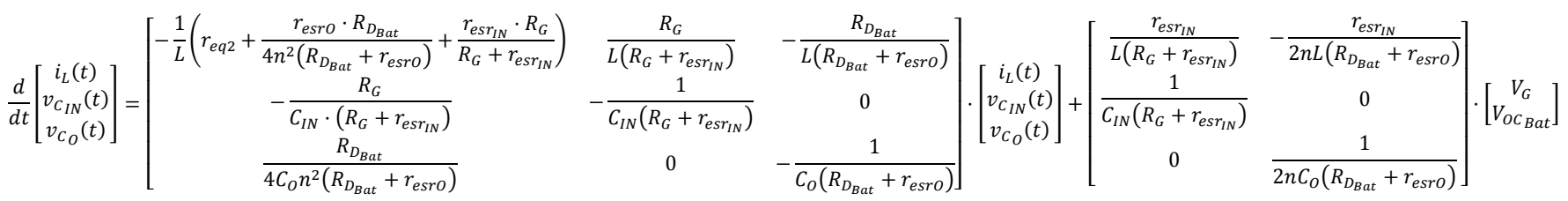


The dynamic resistance of a battery varies significantly depending on the battery state of charge (SOC) and state of health $(\mathrm{SOH})$ [11]. Moreover, the battery terminal voltage will be dependent on these parameters as well as on the charging and discharging current levels. The dynamic resistance together with the instantaneous terminal voltage affect the dc gain of the duty cycle-to-inductor current transfer function and the converter steady state operating point. Therefore, in battery loaded applications, a detailed modeling of the battery has to be performed taking into consideration the variations of the dynamic behavior depending on both aging and SOC. In the end application this will affect the control loop behavior both in short and long term reducing the reliability of the system. Dynamic characterization of lead-acid battery is out of scope of this paper and will be the subject of another work. However, in order to be able to test the accuracy of the derived converter model, several measurements of the battery dynamic resistance and the battery terminal voltage are performed at the converter operating conditions. The batteries used in this experiment are Haze HZB-EV12-26 which are rated for 12 volts and $26 \mathrm{Ah}$. The impedance measurement results are shown in Fig. 8.

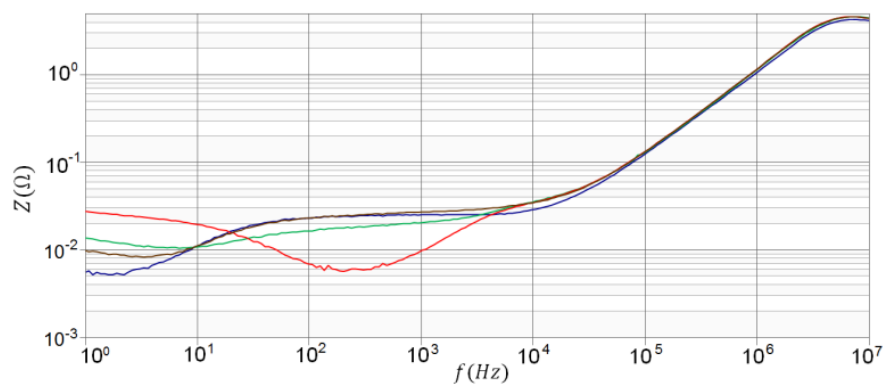

Fig. 8. Battery bank individual impedance measurements.

The battery dynamic resistance value has been taken as the series combination of the four individual battery impedances (a) $1 \mathrm{kHz}$ which is the desired loop crossover frequency. According to the measurements of Fig. 8 the equivalent resistance value is $R_{D_{B a t}} \approx 80 \mathrm{~m} \Omega$.

Fig. 9 shows the simulated gain and phase plots of the duty cycle-to-inductor current transfer function for two cases. Blue line shows the converter operated with battery as a load and the green line presents a pure resistive loading for the same converter power level. It can be observed that due to the low dynamic resistance of the battery the transfer function of the converter behaves similar to a first order system. The complex poles appearing at the converter natural resonant frequency in the pure resistive loading case are separated in the case of battery loading.

Fig. 10 shows the simulated effect of introducing parasitic elements in the converter model. The gain reduction at low frequencies is due to the fact that the parasitic resistances are in the same value range with the battery bank impedance. Ignoring the parasitic elements during the modeling process will result in a deviation of the open loop transfer function crossover frequency location.

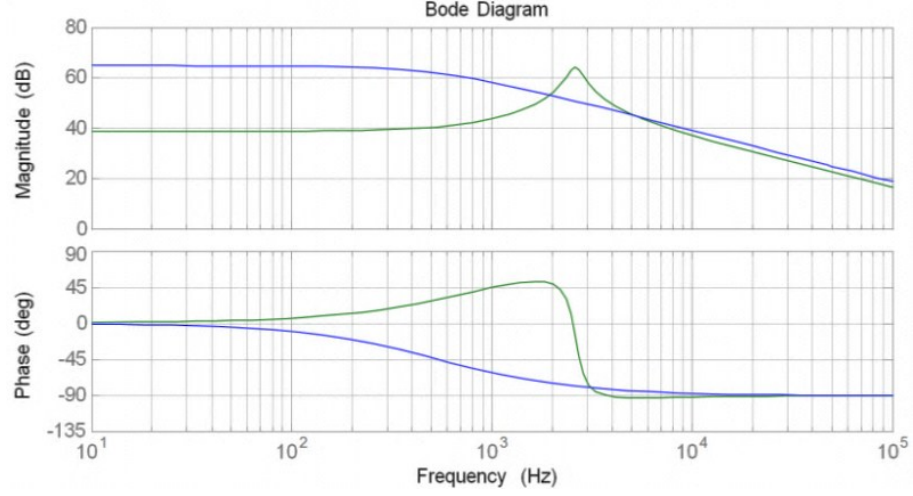

Fig. 9. Calculated converter transfer function with resistive load (green trace) and with a battery as a load (blue trace) for the same power level.

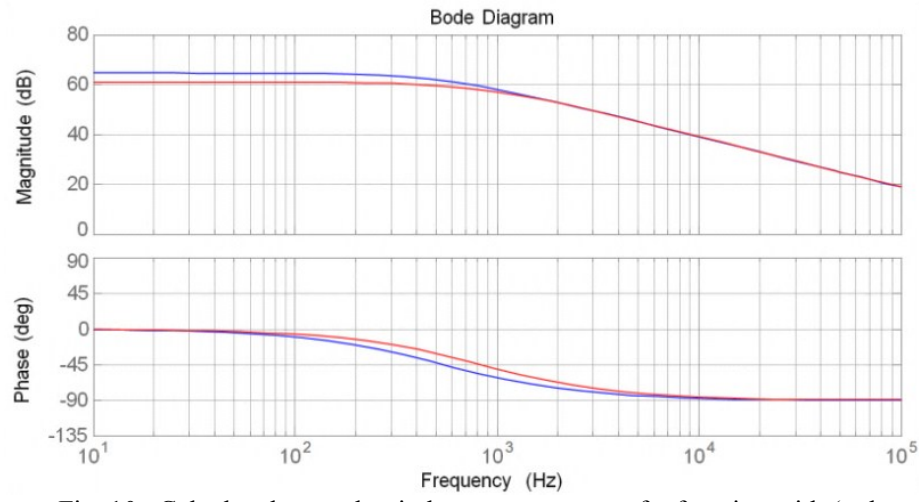

Fig. 10. Calculated control to inductor current transfer function with (red trace) and without (blue trace) parasitic resistances.

\section{IMPLEMENTED PROTOTYPE}

A prototype of PPIBC has been constructed using planar magnetic elements as shown in Fig. 11. The control law has been implemented using TMS320F28035 which is a 32 bit microcontroller. The MOSFETs are driven by IR2110's connected to the microcontroller through ISO7241 capacitive isolators. The inductor current is measured by a LEM Hall effect current transducer, LAS 100-TP, with $\pm 100 \mathrm{~A}$ measurement range. The transducer signal is conditioned by an operational amplifier as shown in Fig. 15 configured in differential mode. The signal is low pass filtered to avoid aliasing and a dc offset is introduced. The gain is adjusted to cover the ADC voltage range of the microcontroller which is from 0 to $3.3 \mathrm{~V}$. Configuration of the control circuit is given in Fig. 12 as a block diagram. Fig. 13 shows the closed loop control block diagram.

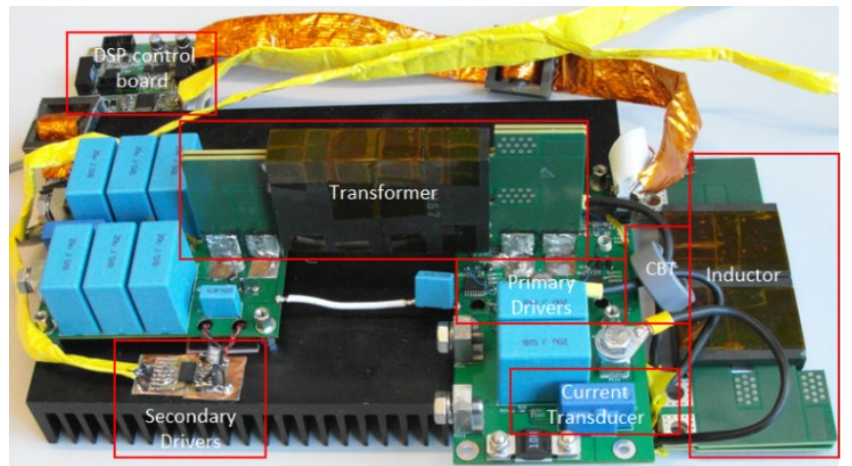

Fig. 11 Converter prototype 


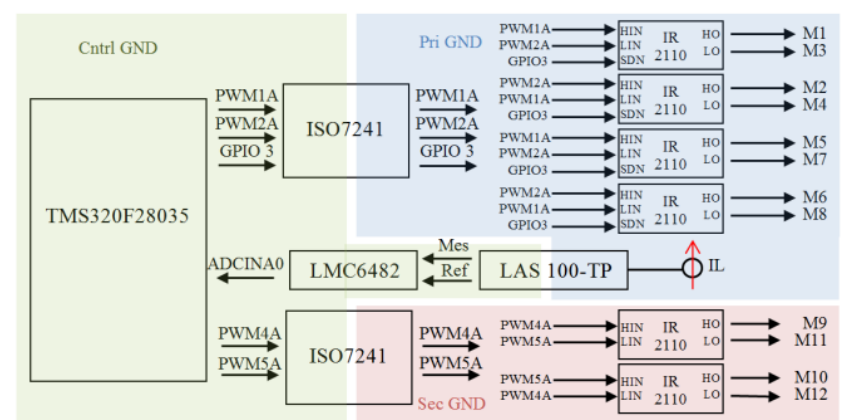

Fig. 12. Control Circuitry Diagram.

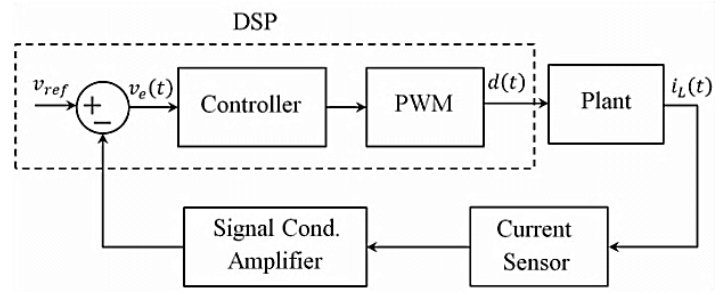

Fig. 13. Closed loop control block diagram.

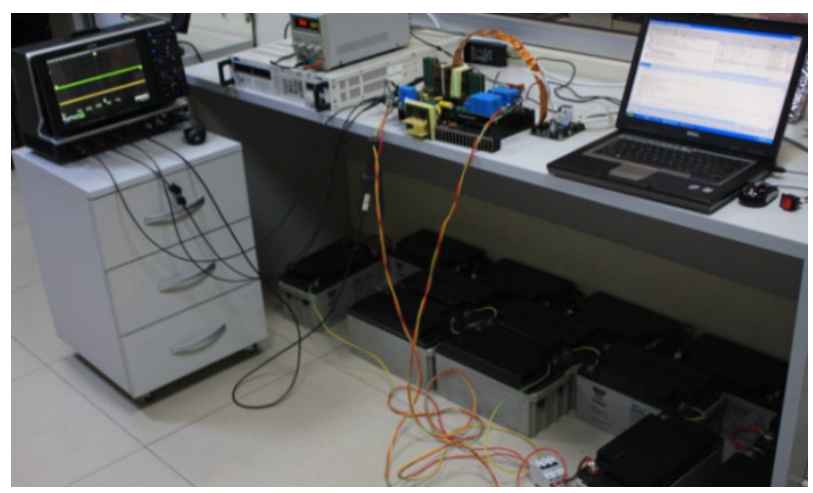

Fig. 14. Experimental setup.

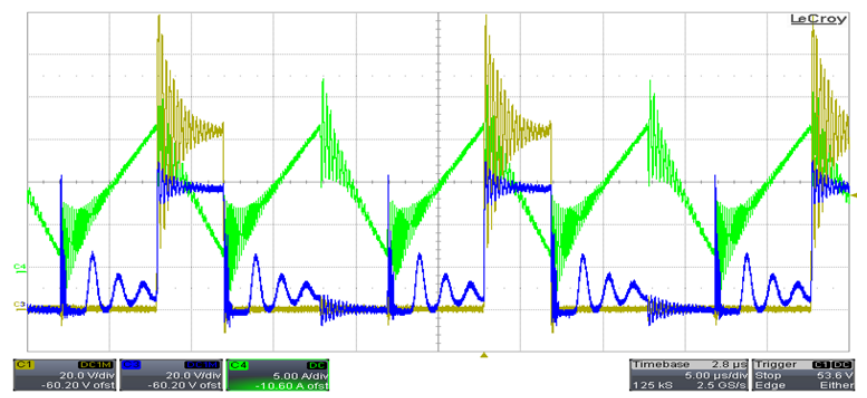

Fig. 15. Converter operating waveforms, primary drain to source voltage (light brown, 20V/div), secondary drain to source voltage (blue, 20V/div) and inductor current (green, $5 \mathrm{~A} / \mathrm{div}$ ). Time scale: $5 \mu \mathrm{s} / \mathrm{div}$.

The test setup of the converter is shown in Fig. 14. The steady state operation of the PPIBC is shown in Fig. 15. High frequency resonances can be observed due to the interaction of parasitic capacitances and inductances in the circuit.
In order to see the effect of the signal conditioning amplifier to the gain and phase of the loop, its transfer function has been derived as in Eq. (23) based on Fig. 16. By using the values given in Table III the signal conditioning amplifier transfer function is drawn. A small signal measurement is also performed in order to verify the accuracy of the calculated transfer function. Fig. 17 shows the measured and calculated signal conditional amplifier transfer function.

Fig. 18 shows the measured and the calculated transfer function of the control algorithm built in DSP together with the sampling, calculation and PWM reconstruction delays.

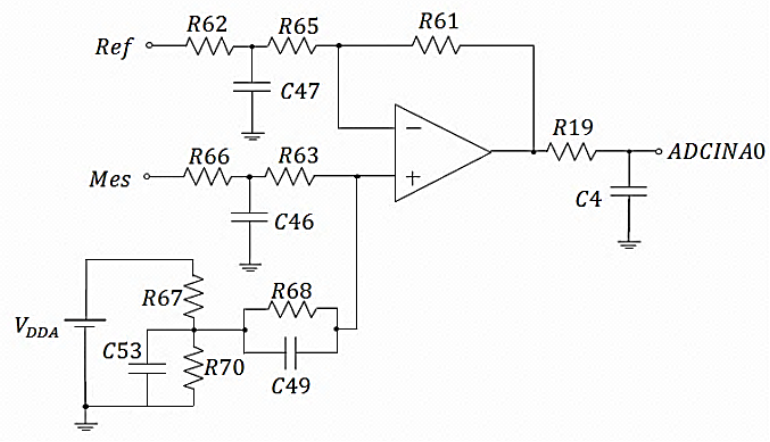

Fig. 16. Signal conditioning amplifier.

TABLE III

PARAMETERS OF THE SignAL CONDITIONING AMPLIFIER

\begin{tabular}{cc}
\hline \hline$R 62, R 66$ & $1 \mathrm{k} \Omega$ \\
$R 65, R 63$ & $100 \mathrm{k} \Omega$ \\
$R 61$ & $220 \mathrm{k} \Omega$ \\
$R 68$ & $330 \mathrm{k} \Omega$ \\
$R 67$ & $1.2 \mathrm{k} \Omega$ \\
$R 70$ & $820 \Omega$ \\
$R 19$ & $270 \Omega$ \\
$C 46$ & $10 \mathrm{nF}$ \\
$C 47, C 53, C 4$ & $100 \mathrm{nF}$ \\
$C 49$ & $100 \mathrm{pF}$ \\
\hline \hline
\end{tabular}

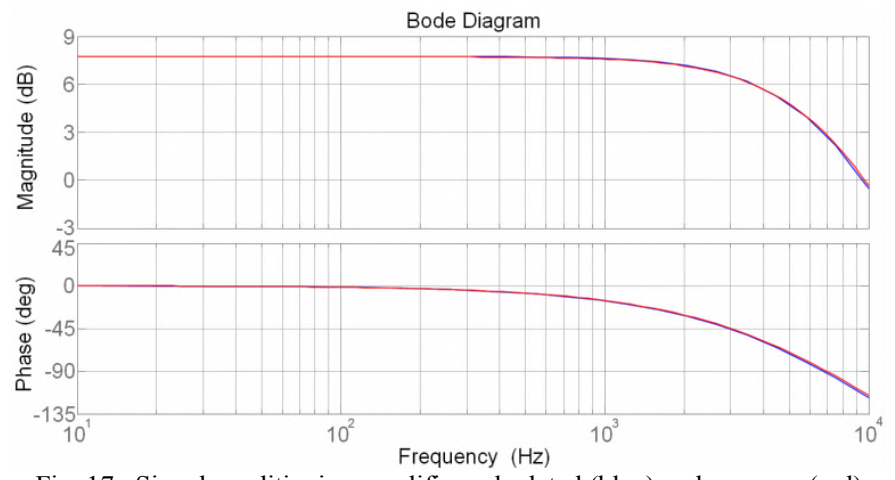

Fig. 17. Signal conditioning amplifier calculated (blue) and measure (red) transfer function.

$$
\begin{gathered}
\frac{V_{A D C I N A 0}}{V_{\text {mes }}}=\frac{R 61 \cdot Z_{\text {eq } 1} \cdot\left(\frac{1}{R 61}+\frac{1}{Z_{\text {eq } 2}}\right)}{\left(R 63+Z_{\text {eq } 1}\right)} \cdot \frac{1}{\left(\frac{R 66}{R 63+Z_{\text {eq } 1}}+C 46 \cdot R 66 \cdot s+1\right)(1+s \cdot R 19 \cdot C 4)} \\
Z_{\text {eq1 }}=R 68\|C 49+R 70\| R 67\left\|C 53 \quad Z_{\text {eq2 }}=R 62\right\| C 47+R 65
\end{gathered}
$$


Due to the fact that the duty cycle-to-inductor current transfer function behaves as a first order system, the implemented control law, shown in Fig.18, is formed by an integrator and a zero placed before the loop crossover frequency to obtain the required phase margin.

The compensated loop transfer function is calculated including the signal conditioning amplifier transfer function, the microcontroller delay and the current transducer gain. The input voltage and the output battery terminal voltage for an inductor current of $I_{L}=10 \mathrm{~A}$ are measured to be $V_{G}=33.6 \mathrm{~V}$ and $V_{o}=56.1 \mathrm{~V}$. These values are used in the obtained model assuming that the output resistance of the input voltage source has a negligible value at the frequencies of interest.

The calculated and measured open loop transfer function is shown in Fig. 19. At low frequencies a small deviation in the phase plot is observed which can be the result of the combined effect of non-ideal integrator implemented inside the DSP and the low frequency increase of the battery dynamic resistance. Both gain and phase plots have close matching due to the fact that parasitic and delay effects have been included during the modeling process.

Fig. 20 shows a current reference step change experiment from $27 \mathrm{~A}$ to $40 \mathrm{~A}$. A settling time of $0.5 \mathrm{~ms}$ is observed which is compatible with the $1 \mathrm{kHz}$ measured crossover frequency of the loop gain. An important detail regarding the relation between crossover frequency and the battery as a load is the possible variation in the loop gain due to the changing current level. This is due to the current dependence of battery terminal voltage which limits the available bandwidth since further increase in gain will lower the phase margin significantly as can be observed in Fig. 19.

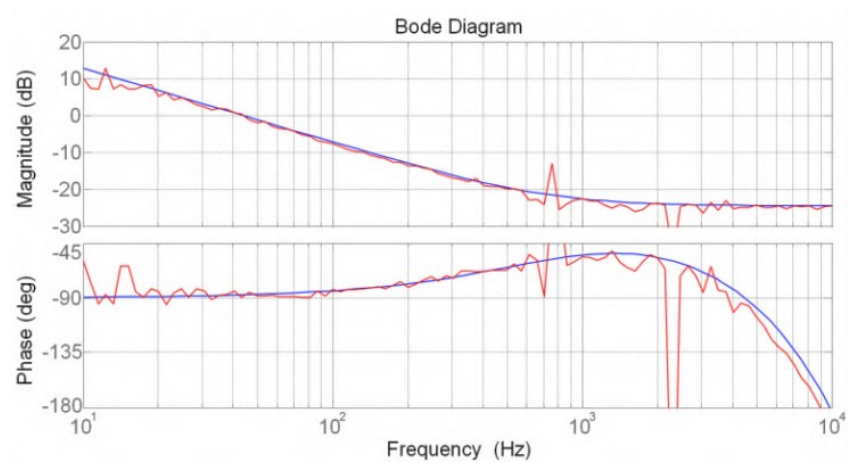

Fig. 18. Gain and phase plots of calculated (blue) and measured (red) control algorithm including the delays.

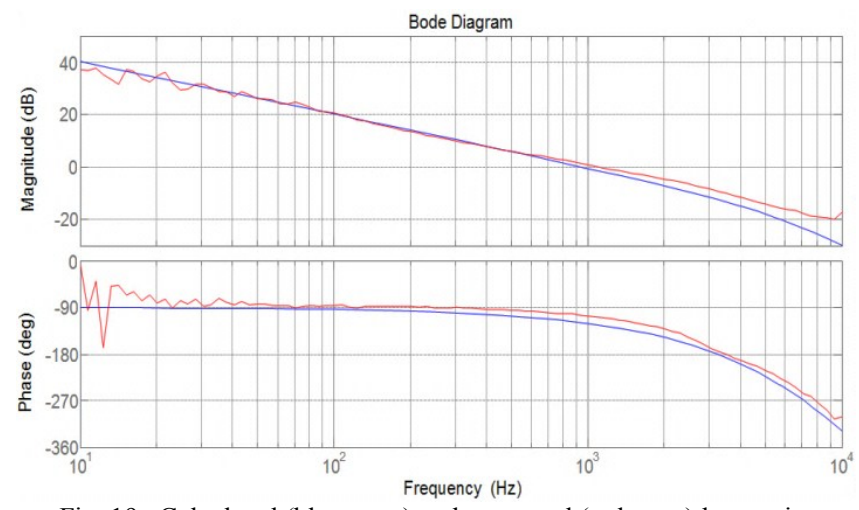

Fig. 19. Calculated (blue trace) and measured (red trace) loop gain.

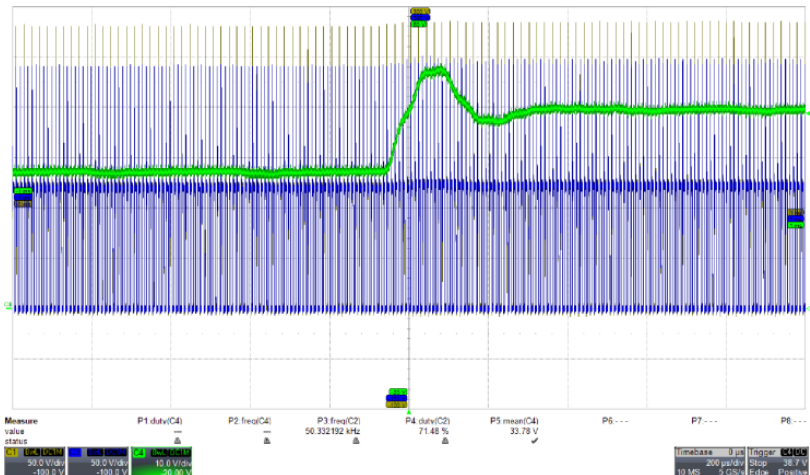

Fig. 20. Current reference step response. Primary drain to source voltage (light brown, $50 \mathrm{~V} / \mathrm{div}$ ), secondary drain to source voltage (blue, $50 \mathrm{~V} / \mathrm{div}$ ) and inductor current (green, 10A/div). Time scale: $200 \mu \mathrm{s} /$ div.

\section{CONCLUSION}

In this paper primary parallel isolated boost converter (PPIBC) loaded with battery has been investigated from modeling and control aspects. A non-ideal converter circuit has been taken into consideration to derive the state space averaged converter model since the series resistance of the battery and the parasitic element values are in the same value range, which is not the case in a pure resistive load for the same power level. The battery bank impedance has also been measured and the impedance value around the crossover frequency has been used. The time delays of the loop due to the digital implementation have also been considered in the model as well as the transfer function of the signal conditioning circuit. Based on this detailed model a simple controller has been designed and implemented. The measured loop gain and phase have been compared to the calculated model achieving close match.

\section{REFERENCES}

[1] R. W. Erickson and D. Maksimovic, Fundamentals of Power Electronics, 2nd ed. Norwell, MA: Kluwer, 2001.

[2] R. D. Middlebrook and S. Cuk, "A general unified approach to modeling switching — Converter power stages," in Proc. IEEE PESC, 1976, pp. 18-34.

[3] W. M. Polivka, P. R. K. Chetty, and R. D. Middlebrook, "State space average modeling of converters with parasitics and storage time modulation," in Proc. IEEE PESC, 1980, pp. 119-143.

[4] Middlebrook, R. D., Cuk, S., "A general unified approach to modeling switching converter power stages", IEEE Power Electronics Specialists Conference Record, pp. 18-34, 1976.

[5] J. Sun, D. M. Mitchell, M. F. Greuel, P. T. Krein, and R. M. Bass, "Averaged modeling of PWM converters operating in discontinuous conduction mode," IEEE Trans. Power Electron., vol. 16, no. 4, pp. 482-492, Jul. 2001.

[6] A. Davoudi, J. Jatskevich, and T. De Rybel, "Numerical state space average value modeling of PWM DC-DC converters operating in DCM and CCM," IEEE Trans. Power Electron., vol. 21, no. 4, pp. 1003-1012, Jul. 2006.

[7] Rim, C. T.; Joung, G.B.; Cho, G.H.; "A state space modeling of nonideal dc-dc converters”, Power Electronics Specialists Conference, 1988. PESC '88 Record., 19th Annual IEEE, vol. 2, pp. 943-950,

[8] Mitchell, D. M., "Switching regulator analysis", McGraw-Hill, 1988, ISBN 0-07-042597-3.

[9] P.J.H. Wingelaar, J.L. Duarte and M.A.M. Hendrix, "Dynamic characteristics of PEM fuel cells", PESC 2005, pp. 1635-1641

[10] M. Nymand, M. A. Andersen, "New primary-parallel boost converter for high-power high-gain applications", Proc. IEEE APEC 2009, pp. 35-39

[11] M. Coleman, W. Gerard Hurley and C. Kwan Lee, "An Improved battery characterization method using a two-pulse load test", IEEE Trans. Energy Conversion, vol. 23, no.2, pp. 708-713, Jun. 2008. 